\title{
The treatment of acute myocardial infarction: the Past, the Present, and the Future
}

European Heart Journal: Acute Cardiovascular Care I(I) 9-I2

(C) The European Society of Cardiology 2012

Reprints and permission:

sagepub.co.uk/journalsPermissions.nav

DOI: | 0.1 | 77//20488726/2438026

acc.sagepub.com

@SAGE

\section{Eugene Braunwald}

\begin{abstract}
Since Herrick's description of the clinical picture of acute myocardial infarction exactly one century ago (19/2), there have been three phases of therapy: Phase I (1912-196I, bed rest and 'expectant' treatment); Phase 2 (196I-1974, the coronary care unit); and Phase 3 (1975-present, myocardial reperfusion). We are now on the cusp of Phase 4, which comprises efforts to reduce myocardial perfusion injury as well as regenerative medicine.
\end{abstract}

\section{Keywords}

Myocardial infarction, coronary care unit, myocardial reperfusion, reperfusion injury

Received: 3 January 2012; accepted 4 January 2012

\section{Introduction}

The year 2012 is the centenary year of the publication of James Herrick's seminal paper: 'Certain clinical features of sudden obstruction of the coronary arteries' ${ }^{1}$ He described the clinical features of two patients with acute myocardial infarction (AMI), one of whom came to postmortem examination and was found to have thrombotic occlusion of a coronary artery. Since this description of AMI, the management of the condition has gone through three major phases and is about to enter the fourth.

\section{The Past}

\section{Phase l: bed rest, expectant treatment}

In his 1912 paper, Herrick wrote: "The importance of absolute rest in bed for several days is clear." At the time, pathologists considered myocardial infarctions to be 'wounds' of the heart and cardiac rupture was feared as a dreaded, invariably fatal complication. Soon, in most hospitals, Herrick's 'several days' of bed rest became two or three weeks. The usual duration of hospitalization in uncomplicated cases was six weeks, followed by a prolonged recovery at home. Few patients were permitted to return to normal activity.

Later authors recommended morphine for pain, as well as digitalis, and caloric and fluid restriction. By 1929, AMI was recognized as a relatively common medical emergency. Levine, in the first book devoted entirely to this condition, ${ }^{2}$ emphasized the frequency and danger of cardiac arrhythmias and recommended quinidine for ventricular tachycardia and intramuscular adrenaline for atrio-ventricular block. Electronic ECG monitoring was not yet available and he suggested that nurses be trained to detect arrhythmias by frequent auscultation.

In the first edition of Harrison's Principles of Internal Medicine, published in 1950 (which was my textbook as a student and which I later edited), treatment of AMI included inhaled oxygen in patients with pulmonary rales and/or cyanosis, as well as subcutaneous atropine and papaverine and sublingual nitroglycerine to relieve coronary spasm. Perhaps most importantly, anticoagulants (both heparin and warfarin were available) were recommended to prevent myocardial reinfarction, pulmonary embolism, and mural thrombosis. ${ }^{3}$

The TIMI Study Group, Cardiovascular Division, Department of Medicine, Brigham and Women's Hospital and Department of Medicine, Harvard Medical School, Boston, MA, USA

\section{Corresponding author:}

Eugene Braunwald, TIMI Study Group, 350 Longwood Avenue, Boston, MA 02II5, USA

Email: ebraunwald@partners.org 
Not only physical rest but also emotional rest was emphasized. As an intern in 1952, we admitted patients with AMI wherever a bed was available on the medical service, but always as far from the nurses' station as possible, so that they would not be disturbed by the commotion, especially the frequent telephone ringing. It was not uncommon for me, when arriving on the medical floor at 6 am to draw blood to be sent for testing, to discover that one of my AMI patients had died quietly during the night. It was quite discouraging to young physicians, because we felt so impotent; older physicians accepted this as 'just the way it was.'

By 1960, when I was a young cardiologist, it was appreciated that AMI was the most common cause of death in North America and Europe, that cardiac rupture was, in fact, an uncommon complication and that prolonged bed rest, which had been routine since Herrick's day, could actually be harmful in some patients by leading to venous thrombosis and fatal pulmonary thromboembolism. In uncomplicated cases, the duration of absolute bed rest was shortened to about five days, the tempo of ambulation was gradually increased, and the duration of hospitalization was shortened to about a month.

In retrospect, the management of AMI during Phase I may be considered to have been 'expectant,' with rest, relief of pain, anticoagulation, and coronary vasodilation, all of which were of questionable benefit. During this period, which marked the first half century after Herrick's paper, mortality remained stubbornly high. Nevertheless, during Phase 1, much was learned about the clinical manifestations, natural history and electrocardiographic features of AMI. It became clear that ventricular arrhythmias were the most common causes of death.

\section{Phase 2: the coronary care unit}

This phase began in 1961 with a paper by Desmond Julian, then a cardiology registrar at Edinburgh's Royal Infirmary, which described what later would be known as the Coronary Care Unit. ${ }^{4}$ Four separate components came together in these units: (1) the segregation of patients with AMI into specialized intensive care units - designated areas of a hospital in which trained staff, specialized equipment, including monitors, catheters, pacemakers, drugs, and frequently cardiologists were all at hand; (2) continuous electrocardiographic monitoring of cardiac rhythm with audible alarms for serious arrhythmias; (3) the training of medical and nursing staff in closed chest resuscitation; and perhaps most importantly (4) providing trained nurses with the authority and responsibility to perform this procedure, including external defibrillation, in the absence of a physician. The introduction of coronary care units radically reduced deaths from ventricular fibrillation, complete heart block, and other potentially fatal arrhythmias, and thereby reduced the early hospital mortality of AMI by half - from about $30 \%$ that it had been during the previous decade to about $15 \%$.
The use of coronary care units swept rapidly and within five years the concept had become accepted and implemented in almost all general hospitals in the industrialized world. Coronary care units brought two issues into sharp relief. The first was the high mortality from AMI before patients reached the unit, and often while waiting in a crowded Emergency Room. This led to more rapid deployment of ambulances and expedited assessment in emergency departments of patients with chest pain and other suspicious clinical manifestations of AMI. To accelerate treatment, physicians or trained emergency medical technicians in some areas rode in well-equipped ambulances, monitored the patients, and, when necessary, performed resuscitation prior to hospital arrival. ${ }^{5}$ The second issue was that in patients who reached the coronary care unit and in whom arrhythmic death had been prevented or treated successfully, the usual cause of death was failure of the left ventricular pump. This resulted most commonly from large infarcts, which in turn were related to a marked imbalance between myocardial oxygen supply and demand. In the early 1970s, our group's efforts in experimental animals were devoted to restoring this balance, both by reducing oxygen demand with beta-adrenergic blockers ${ }^{6}$ and by improving oxygen supply by means of myocardial reperfusion. ${ }^{78}$ It is of interest that, in his 1912 paper, Herrick had been prescient when he wrote: "The hope for the damaged myocardium lies in the direction of securing a supply of blood through friendly neighboring vessels so as to restore as far as possible its functional integrity."1

\section{The Present}

\section{Phase 3: myocardial reperfusion}

This phase was initiated in 1975 by Chazov et al. who lysed coronary thrombi by infusing streptokinase directly into the blocked coronary arteries of patients with AMI. ${ }^{9}$ We then demonstrated that timely reperfusion actually salvaged severely ischemic myocardium. ${ }^{10}$ Although intracoronary fibrinolysis became routine in a few cardiac centers, it was not suitable for widespread adoption for logistical reasons. In 1986, the GISSI investigators, in one of the first cardiac mega-trials, demonstrated a reduction in mortality by streptokinase infused intravenously. ${ }^{11}$ In the first TIMI trial, we found that patency of the infarct-related coronary artery, however it was achieved, was associated with prolonged survival, ${ }^{12}$ leading to the 'early open artery theory.'

During the last quarter century, myocardial reperfusion has been improved progressively by a number of key steps: (1) the development of tissue plasminogen activators, more potent in lysing thrombi than streptokinase ${ }^{13}$; (2) the addition of aspirin ${ }^{14}$ and then more potent antiplatelet agents ${ }^{15}$ to the fibrinolytic; (3) the use of percutaneous coronary angioplasty following AMI in place of fibrinolytics ${ }^{16}$; (4) the addition of stents ${ }^{17}$ - first bare metal then drug-eluting stents - following intracoronary balloon inflation; and most 
recently (5) by aspiration thrombectomy prior to coronary stenting. ${ }^{18}$ As a consequence of these measures, each of which improved clinical outcomes, in-hospital mortality from AMI in the general population again declined by half, from $15 \%$ to about $7.5 \%$ and it is now as low as 3.5\% in patients who are enrolled in clinical trials. Most patients in industrialized nations are now receiving the benefits of timely (early) reperfusion therapy.

While myocardial reperfusion obviously represents a major step forward, it is not an unmixed blessing. Although it reduces ischemic cell death it also injures the surviving myocardium. In the 1960s, well before the first human reperfusion studies were carried out, Jennings et al. ${ }^{19}$ and Krug et al. ${ }^{20}$ demonstrated impaired reperfusion after release of a temporary coronary occlusion. Kloner et al. reported that reperfusion caused microvascular damage with swelling of capillary endothelial cells and of myocytes, leading to what was termed the 'no reflow phenomenon.'21 Areas of noreflow have been found to be associated with infarct expansion in animals and a high mortality in patients. ${ }^{22}$ Myocardial reperfusion is often accompanied by myocardial injury, commonly known as lethal reperfusion injury. Indeed, in 1985 , we referred to myocardial reperfusion as 'a doubleedged sword. ${ }^{23}$

During the past decade, three paradoxes have been incriminated as playing a role in lethal myocardial reperfusion injury ${ }^{24}$ : (1) the calcium paradox, which raises intracytoplasmic calcium concentration; (2) the oxygen paradox, in which reperfusion raises myocardial $\mathrm{pO}_{2}$, causing the formation of toxic reactive oxidants; and (3) the $\mathrm{pH}$ paradox, in which a physiologic $\mathrm{pH}$ is suddenly restored in the ischemic zone in which the $\mathrm{pH}$ had declined. It has been postulated that these paradoxes are involved in opening a channel in the inner mitochondrial membrane, the so-called mitochondrial permeability transition pore, and that the resultant rapid influx of calcium and reactive oxygen species through these pores damages mitochondria, which in turn fail to synthesize high energy phosphate, thereby leading to myocyte death.

\section{The Future}

\section{Phase 4: the prevention of lethal myocardial reperfusion injury}

Many interventions to prevent or diminish lethal myocardial reperfusion injury have been studied..$^{25}$ Two are particularly interesting and have shown some promise, both in preclinical studies as well as in small, but intriguing, proof of principle clinical trials. The first is an extension of the principle of cardiac preconditioning, in which brief cycles of alternating ischemia and reflow prior to a sustained occlusion reduce the size of the subsequent infarct. ${ }^{26}$ It has been observed that this cyclic ischemia can be induced in an organ or tissue other than the heart, yet remain cardioprotective, an intervention termed 'remote ischemic preconditioning. ${ }^{27}$ The clinical value of ischemic preconditioning - local or remote - is useful only when the timing of the prolonged ischemia, such as that induced by cardiac surgery or a percutaneous coronary intervention, is known. It is not applicable to patients with the usual AMI in whom the time when the coronary occlusion will occur is, of course, not known. However, 'postconditioning' in which the cyclic periods of ischemia and reflow are begun immediately after the prolonged occlusion is relieved - has also been shown to reduce ischemic injury ${ }^{28}$ and it too can be effective when carried out remotely. ${ }^{29}$ Conditioning can also be begun during the occlusion and it is then referred to as 'perconditioning.' The mechanism of protection afforded by these different forms of conditioning appears to be prevention of opening of the above-mentioned mitochondrial permeability transition pore. ${ }^{24}$ However, there is continuing debate about the specific signals acting on the pore.

Two clinical applications of perconditioning in patients with AMI have been reported. Botker et al. found significant reduction in infarct size in patients in whom intermittent arm occlusion with a blood pressure cuff was performed in the ambulance prior to primary percutaneous coronary intervention. ${ }^{30}$ The second is pharmacologic conditioning, in which ciclosporin A was infused intravenously just prior to balloon inflation. Following encouraging preclinical studies by Griffiths and Halestrap, ${ }^{31}$ Piot et al. conducted a three-center clinical trial and showed that ciclosporin A reduced infarct size. ${ }^{32}$ Although these two approaches may appear to be dissimilar superficially, both seem to have a similar fundamental mechanism, i.e. interfering with the opening of the mitochondrial permeability transition pores, and thereby preventing lethal myocardial reperfusion injury.

It has been estimated that timely reperfusion can salvage approximately $50 \%$ of severely ischemic myocardium ${ }^{33}$ and that prevention of lethal myocardial reperfusion injury should prevent the necrosis of an additional $40 \% .{ }^{24}$ If the latter is successful, it would further substantially reduce the mortality from AMI.

As we enter the second century following Herrick's remarkable paper, substantial further research on the prevention of lethal myocardial reperfusion injury should, and undoubtedly will, be carried out. This will involve both preclinical and clinical studies, culminating in large trials with clinical endpoints. ${ }^{34}$ In addition, during the next few years, we will see an acceleration of therapy with a variety of autologous progenitor cells administered post-infarction in an effort to regenerate new myocardium. I expect that many of these investigations will be published in the pages of this important new journal.

Congratulations and best wishes for a successful publishing endeavor in an important aspect of cardiology.

\section{Funding}

This research received no specific grant from any funding agency in the public, commercial, or not-for-profit sectors. 


\section{Conflict of interest}

None declared.

\section{References}

1. Herrick JB. Certain clinical features of sudden obstruction of the coronary arteries. JAMA 1912; 59: 2015-20.

2. Levine SA. Coronary thrombosis: its various clinical features. Baltimore: Williams \& Wilkins, 1929.

3. Harrison TR and Resnik WH. Etiologic aspects of heart disease (including treatment of the different etiologic types). In Harrison TR, Beeson PB, Thorn GW, et al. (eds). Principles of internal medicine. New York: Blackiston, 1950, pp.1287-89.

4. Julian DG. Treatment of cardiac arrest in acute myocardial ischemia and infarction. Lancet 1961; 840-44.

5. Pantridge JF and Geddes JS. A mobile coronary care unit in the management of myocardial infarction. Lancet 1967; 271-73.

6. Maroko PR, Kjekshus JK, Sobel BE, et al. Factors influencing infarct size following experimental coronary artery occlusion. Circulation 1971; 43: 67-82.

7. Ginks WR, Sybers PR, Maroko PR, et al. Coronary artery reperfusion. II. Reduction of myocardial infarct size at one week after the coronary occlusion. J Clin Invest 1972; 51: 2717-23.

8. Maroko PR and Braunwald E. Modification of myocardial infarct size after coronary occlusion. Ann Intern Med 1973; 79: 720-33.

9. Chazov EI, Matveeva LS, Mazaev AV, et al. Intracoronary administration of fibrinolysin in acute myocardial infarction. Terapeuticheskii Arkhiv 1976; 48: 8-19.

10. Markis JE. Malagold M. Parker JA, et al. Myocardial salvage after intracoronary thrombolysis with streptokinase in acute myocardial infarction: assessment of intracoronary thallium-201. N Engl J Med 1981; 305: 777-82.

11. Gruppo Italiano per lo Studio della Streptochinasi nell'Infarto Miocardico (GISSI). Effectiveness of intravenous thrombolytic treatment in acute myocardial infarction. Lancet 1986; 397-402.

12. Dalen JE, Gore JM. Braunwald E, et al. Six and twelvemonth follow-up of the Phase I Thrombolysis in Myocardial Infarction (TIMI) Trial. Am J Cardiol 1988; 62: 179-85.

13. TIMI Study Group. The Thrombolysis in Myocardial Infarction (TIMI) Trial. N Engl J Med 1985; 312: 932-36.

14. ISIS-2 Collaborative Group. Randomized trial of intravenous streptokinase, oral aspirin, both, or neither among 17187 cases of suspected acute myocardial infarction: ISIS2. Lancet 1988; 349-60.

15. Sabatine MS, Cannon CP, Gibson CM, et al. Addition of clopidogrel to aspirin and fibrinolytic therapy for myocardial infarction with ST-segment elevation. $N$ Engl J Med 2005; 352: 1179-89.

16. Keeley EC, Boura JA and Grines CL. Primary angioplasty versus intravenous thrombolytic therapy for acute myocardial infarction: a quantitative review of 23 randomized trials. Lancet 2003; 361: 13-20.

17. Zhu MM, Feit A, Chadow H, et al. Primary stent implantation compared with primary balloon angioplasty for acute myocardial infarction. A meta analysis of randomized clinical trials. Am J Cardiol 2001; 88: 297-301.

18. Brodie BR. Aspiration thrombectomy with primary PCI for STEMI: review of the data and current guidelines. J Invasive Cardiol 2011; 22: 2B-5B.

19. Jennings RB, Sommers HM, Smyth GA, et al. Myocardial necrosis induced by temporary occlusion of a coronary artery in the dog. Arch Pathol 1960; 70: 68-78.

20. Krug A, Du Mesnil de Rochemont R and Korb G. Blood supply of the myocardium after temporary coronary occlusion. Circ Res 1966; 19: 57-62.

21. Kloner RA, Ganote CE and Jennings RB. The "no-reflow" phenomenon after temporary coronary occlusion in the dog. J Clin Invest 1974; 54: 1496-508.

22. Ndrepepa G, Tiroch K, Fusaro M, et al. 5-year prognostic value of no-reflow phenomenon after percutaneous coronary intervention in patients with acute myocardial infarction. J Am Coll Cardiol 2010; 55: 2383-89.

23. Braunwald E and Kloner RA. Myocardial reperfusion: a double-edged sword? J Clin Invest 1985; 76: 1713-19.

24. Yellon DM and Hausenloy DJ. Myocardial reperfusion injury. $N$ Engl J Med 2007; 357: 1121-35.

25. Schwartz Longacre L, Kloner RA, Arai AE, et al. New horizons in cardioprotection: recommendations from the 2010 National Heart, Lung and Blood Institute Workshop. Circulation 2011; 124: 1172-79.

26. Murry CE, Jennings RB and Reimer KA. Preconditioning with ischemia: a relay of lethal cell injury in ischemic myocardium. Circulation 1986; 74: 1124-36.

27. Hausenloy DJ and Yellon DM. Remote ischemic preconditioning: Underlying mechanisms and clinical application. Cardiovasc Res 2008; 79: 377-86.

28. Zhao Z-Q, Corvera JS, Halkos ME, et al. Inhibition of myocardial injury by ischemic postconditioning during reperfusion: Comparison with ischemic preconditioning. Am J Physiol Heart Circ Physiol 2003; 285: H579-H588.

29. Kerendi F, Kin H, Halkos ME, et al. Remote postconditioning: brief renal ischemia and reperfusion applied before coronary artery reperfusion reduces myocardial infarct size via endogenous activation of adenosine receptors. Basic Res Cardiol 2005; 100: 404-12.

30. Botker HE, Kharbanda R, Schmidt MR, et al. Remote ischemic conditioning before hospital admission, as a complement to angioplasty, and effect on myocardial salvage in patients with acute myocardial infarction: a randomized trial. Lancet 2010; 375: 727-34.

31. Griffiths EJ and Halestrap AP. Protection by Cyclosporin A of ischemia/reperfusion-induced damage in isolated rat hearts. J Mol Cell Cardiol 1993; 25: 1461-69.

32. Piot $\mathrm{C}$, Croisille $\mathrm{P}$, Staat $\mathrm{P}$, et al. Effect of cyclosporine on reperfusion injury in acute myocardial infarction. $N$ Engl $J$ Med 2008; 359: 473-81.

33. Miura T and Miki T. Limitation of myocardial infarct size in the clinical setting: current status and challenges in translating animal experiments into clinical therapy. Basic Res Cardiol 2008; 1031: 501-12.

34. Braunwald E. Clinical efforts to reduce myocardial infarct size - the next step. J Cardiovasc Pharm Ther 2011; 16: $349-53$. 